\title{
Expression of Caspase Family and Muscle- and Apoptosis-Specific Genes during Skeletal Myogenesis in Mouse Embryo
}

\author{
Teppei IKEDA $^{1)}$, Tomonori KANAZAWA ${ }^{1)}$, Saori OTSUKA ${ }^{1)}$, Osamu ICHII ${ }^{1)}$, Yoshiharu HASHIMOTO ${ }^{1)}$ and \\ Yasuhiro $\mathrm{KON}^{1) *}$ \\ ${ }^{1)}$ Laboratory of Anatomy, Department of Biomedical Sciences, Graduate School of Veterinary Medicine, Hokkaido University, Sapporo \\ 060-0818, Japan
}

(Received 15 April 2009/Accepted 4 May 2009)

ABSTRACT. The caspases (Casps) are a family of cysteine proteases that are known to regulate apoptotic signaling. Apoptosis by activation of Casp is strongly associated with embryonal development and regeneration in many organs, therefore indicating that disorders caused by homozygous mutation in Casp genes can result in embryonic lethality. In the present study, the authors investigated the causative relationship between skeletal myogenesis and the activation of Casps by analyzing their dynamics during mouse embryogenesis. Individual myogenetic tissues were obtained from C57BL/6 mouse embryos aged 12.5-17.5 days post-conception (dpc), and the expression of Casps was analyzed by histochemical and molecular biological methods. Immunoreactions for Casp-3, -9 and -12 were detected first in myoblasts, increasing according to embryonal development, as a result of which myoblasts differentiated into myotube cells. On the other hand, the immunoreaction for ssDNA, which is well-known as an apoptosis marker, was little detected during the skeletal myogenesis. Quantification analysis for Casp mRNA expression by RT-PCR as well as by in situ hybridization showed a peak at 15.5 dpc but a decrease at $17.5 \mathrm{dpc}$. Similar dynamics were detected for Myodl mRNA, one of the muscle regulatory factors, but not for Fasl, Bax and Rock1, apoptosis-associated factors during skeletal myogenesis. These results suggest that the activation of Casps in skeletal myogenesis is deeply associated with myoblast differentiation, but not directly related to apoptosis.

KEY WORDS: apoptosis, caspase, mouse, myogenesis, skeletal muscle.

J. Vet. Med. Sci. 71(9): 1161-1168, 2009

In skeletal myogenesis, myofibroblasts begin to differentiate from mesenchymal stem cells in the somitic mesoderm, and then fuse into multinucleated myotubes [23, 28]. The myoblasts proliferate by repeating cell division, and then differentiate into myocytes by expressing muscle-specific genes at the appropriate times. These muscle-specific genes code some muscle regulatory factors (MRF), including Myf5, MyoD, myogenin and MRF4 [1]. Myf5 and MyoD, activated in the early myogenetic stage, are essential factors for differentiation from mesenchymal stem cells into myoblasts and for the proliferation and survival of myoblasts [18]. It is reported that neither differentiation nor myogenesis completely occur in their double-knockout mice [26]. Myogenin and MRF4, appearing after expression of Myf5 and MyoD, regulate the myoblast differentiation and myotube maturity [24, 31]. In addition, the myocyte enhancer factor 2 (MEF2) family, one of the transcription factors associated with MRF proteins, binds A-T rich sites in the promoter regions of muscle-specific genes, including myogenin and Mrf4 [3]. A direct interaction between MEF2 and MRFs activates transcription mutually, finally resulting in the initiation of the myogenesis [19].

In these processes, myoblasts undergo some dynamic morphological changes, including resolution and reconstruction of cytoskeletal actin filaments, fusion of the cell membrane and reorganization of cytoplasmic organella [9,

\footnotetext{
* Correspondence to: Kon, Y., Laboratory of Anatomy, Department of Biomedical Sciences, Graduate School of Veterinary Medicine, Hokkaido University, Sapporo 060-0818, Japan. e-mail: y-kon@vetmed.hokudai.ac.jp
}

$25,27,35]$. Interestingly, these morphologic changes in myoblast differentiation are extremely similar to those in the apoptotic process, showing that phenomena such as resolution of the cytoskeletal protein, blebbing of the cell membrane and packaging of cytoplasmic organella into the apoptotic body are common between myogenesis and apoptosis $[4,12]$.

The caspases (Casps) are a family of cysteine proteases that are known to regulate apoptotic signaling [29]. Since embryonic lethality is induced by knockout of several Casp genes, the Casp family is an essential factor for embryogenesis $[11,16,17,30]$. In agreement with these reports, it has been clarified that apoptosis activated by several signaling cascades is strongly associated with embryogenesis and regeneration in the whole body, including the liver, thymus and brain $[15,33,36]$. Apoptosis signaling cascades are classified into 3 types: 1) the pathway via death receptors, 2) the pathway via mitochondria, and 3) the pathway from endoplasmic reticulum (ER). Interestingly, it has been suggested that ER stress which causes the activation of caspase12 from procaspase-12 exerts a positive effect on myofiber formation [20, 21]. Furthermore, a substrate of Casp-12 is the procaspase- 9 and that ER stress triggers a specific cascade involving Casp-12, -9, and -3 [21]. Casp-3 as an effector is thought to be directly associated with myogenesis as well because absence of the Casp-3 gene in mouse myoblast, C2C12 cells, results in suppression of differentiation [8]. However, there is no report clarifying the relations between myogenesis and expression timing of Casp family in embryo. 
Table 1. Primer pairs for investigation of Casp family, muscle-specific genes and apoptosis-specific genes

\begin{tabular}{|c|c|c|c|c|}
\hline $\begin{array}{c}\text { Genes } \\
\text { (Accession) }\end{array}$ & $\begin{array}{l}\left.\text { Primer Sequence (5'- } 3^{\prime}\right) \\
\text { F: Forward, R: Reverse }\end{array}$ & $\begin{array}{l}\text { Primer Position } \\
\quad\left(5-3^{\prime}\right)(\mathrm{bp})\end{array}$ & $\begin{array}{l}\text { Product Size } \\
\quad \text { (bp) }\end{array}$ & Remarks \\
\hline Casp-1 & F: CGCACACAGCAATTGTGGTT & $92-111$ & 511 & for Fig. 1 \\
\hline (NM_009807) & R: AAACTTGAGGGTCCCAGTCA & $602-583$ & & \\
\hline$\overline{C a s p}-2$ & F: GGCCCAGCGTTTGTTTGTTT & $29-48$ & 542 & For Fig. 1 \\
\hline \multirow[t]{2}{*}{ (NM_007610) } & R: TCCGTAGCATCTGTGGATAG & $570-551$ & & \\
\hline & F: GGAGCTTGGAACGCTAAGAA & $36-55$ & 499 & for Figs. 1 and 5 \\
\hline Casp-3 & R: GAGTTTCGGCTTTCCAGTCA & $534-515$ & & \\
\hline \multirow[t]{2}{*}{ (NM_009810) } & F: GGAGCAAGTCAGTGGACTCT & $131-150$ & 370 & For Fig. 6 \\
\hline & R: TCGCCTCTGAAGAAGCTAGT & $500-481$ & & \\
\hline Casp-4 & F: GTGCGAAAGAACTGAGGCTT & $9-28$ & 482 & For Fig. 1 \\
\hline (NM 007609) & R: TTTAGCCCCATACCTCAGTG & $490-471$ & & \\
\hline Casp-6 & F: CATGACAGAAACCGATGGCT & $56-75$ & 513 & For Fig. 1 \\
\hline (NM 009811) & R: ACGTTGTCCAGCTTGTCTGT & $568-549$ & & \\
\hline Casp-7 & F: TGGGAACGATGACCGATGAT & $181-200$ & 521 & For Fig. 1 \\
\hline (NM_007611) & R: CATCGGTCTCCCCTAAAATG & $701-682$ & & \\
\hline Casp-8 & F: CGTGGAACAGGAAGTGAGTA & $74-93$ & 464 & For Fig. 1 \\
\hline \multirow{2}{*}{ (NM_009812) } & R: TGACCCTGTAGGGAGAAATC & $537-518$ & & \\
\hline & F: CGCGACATGATCGAGGATAT & $352-371$ & 508 & For Figs. 1 and 5 \\
\hline Casp-9 & R: TGTTGATGATGAGGCAGTGG & $859-840$ & & \\
\hline \multirow[t]{3}{*}{ (NM_015733) } & F: СТТССТСТСТТСАТСТССТG & $451-470$ & 339 & For Fig. 6 \\
\hline & R: ACACAGACATCATGAGCTC & $779-760$ & & \\
\hline & F: CAGGAGGACACATGAAAGAG & $26-45$ & 508 & For Figs. 1 and 5 \\
\hline Casp-12 & R: CTCCTTCTCCATCACTGGAT & $533-514$ & & \\
\hline \multirow[t]{2}{*}{ (NM_009800) } & F: TGACCTGGTGGAGAAGAATG & $101-120$ & 320 & For Fig. 6 \\
\hline & R: GAGGAGCTGTCAGCATTAGA & $420-401$ & & \\
\hline Myhl & F: AGAAGAACCTGGAGCAGACG & $5453-5471$ & 268 & For Figs. 1 and 6 \\
\hline (NM 030679) & R: TGCAGTTTGTCCACAAGGTC & $5720-5701$ & & \\
\hline$\overline{M y o d l}$ & F: CACTACAGTGGCGACTCAGACGCG & $762-785$ & 144 & For Figs. 1 and 6 \\
\hline (NM_010866) & R: CCTGGACTCGCGCACCGCCTCACT & $905-882$ & & \\
\hline $\bar{F}$ Fasl & F: CATCACAACCACTCCCACTG & $383-402$ & 187 & For Fig. 6 \\
\hline (NM_010177) & R: AGGCTTTGGTTGGTGAACTC & $569-550$ & & \\
\hline Bax & F: TGCAGAGGATGATTGCTGAC & $350-369$ & 235 & For Fig. 6 \\
\hline (NM_007527) & R: TCTTGGATCCAGACAAGCAG & $584-565$ & & \\
\hline Rockl & F: TGCCATGTTAAGTGCCACAG & $4265-4284$ & 218 & For Fig. 6 \\
\hline (NM 009071) & R: GATCTTGTTGACAGCGTTCG & $4482-4463$ & & \\
\hline $\bar{A} c t b$ & F: TGTTACCAACTGGGACGACA & $304-323$ & 165 & For Figs. 1 and 6 \\
\hline (NM_007393) & R: GGGGTGTTGAAGGTCTCAAA & $468-449$ & & \\
\hline
\end{tabular}

Myh1: Myosin heavy polypeptide 1. Myod1: Myogenic differentiation 1. Actb: Actin beta.

Fasl: Fas ligand. Bax: Bcl-associated X protein. Rockl: Rho-associated coiled-coil containing protein kinase 1.

For Fig. 1: LMD-RT-PCR. For Fig. 5: in situ hybridization. For Fig. 6: quantitative RT-PCR.

In the present study, the authors investigated the relationship between myogenesis and the Casp family, paying special attention to Casp-3, -9 and -12 , a series of factors including the pathway from ER, examining mouse embryonal tissues by histological and molecular biological techniques.

\section{MATERIALS AND METHODS}

Animals: For the observations in embryos, male and female C57BL/6 mice were purchased from an experimental animal breeder (Japan SLC, Hamamatsu, Japan) and maintained in our animal facility until the investigation began. When a vaginal plug was confirmed on the morning after mating on the previous evening, the period of pregnancy was designated at 0.5 day post-conception (dpc). Embryos at 12.5 17.5 dpc and newborn mice were obtained by cervical dislocation, and analyzed by the following histo- logical and molecular biological procedures. In the experimental protocols for animal care and handling, the investigators adhered to the Guide for the Care and Use of Laboratory Animals, Hokkaido University, Graduate School of Veterinary Medicine.

Laser microdissection (LMD) and reverse transcriptasepolymerase chain reaction (RT-PCR): Five-micrometerthick cryosections obtained from fresh embryos at 13.5$17.5 \mathrm{dpc}$ were prepared for mounting on glass slides precoated with LMD film (Meiwafosis, Osaka, Japan) and fixed with absolute alcohol containing 5\% acetic acid for 3 min at $4{ }^{\circ} \mathrm{C}$. After staining with $1 \%$ toluidine blue for $10 \mathrm{sec}$, LMD targeting dorsal skeletal muscle tissues was performed by using Ls-Pro300, according to the manufacturer's protocol (Meiwafosis, Osaka, Japan). All procedures were done in the RNase-free condition.

Total RNAs purified with RNAqueous (Ambion, Foster City, CA, U.S.A.) and Turbo DNase (Ambion), were 


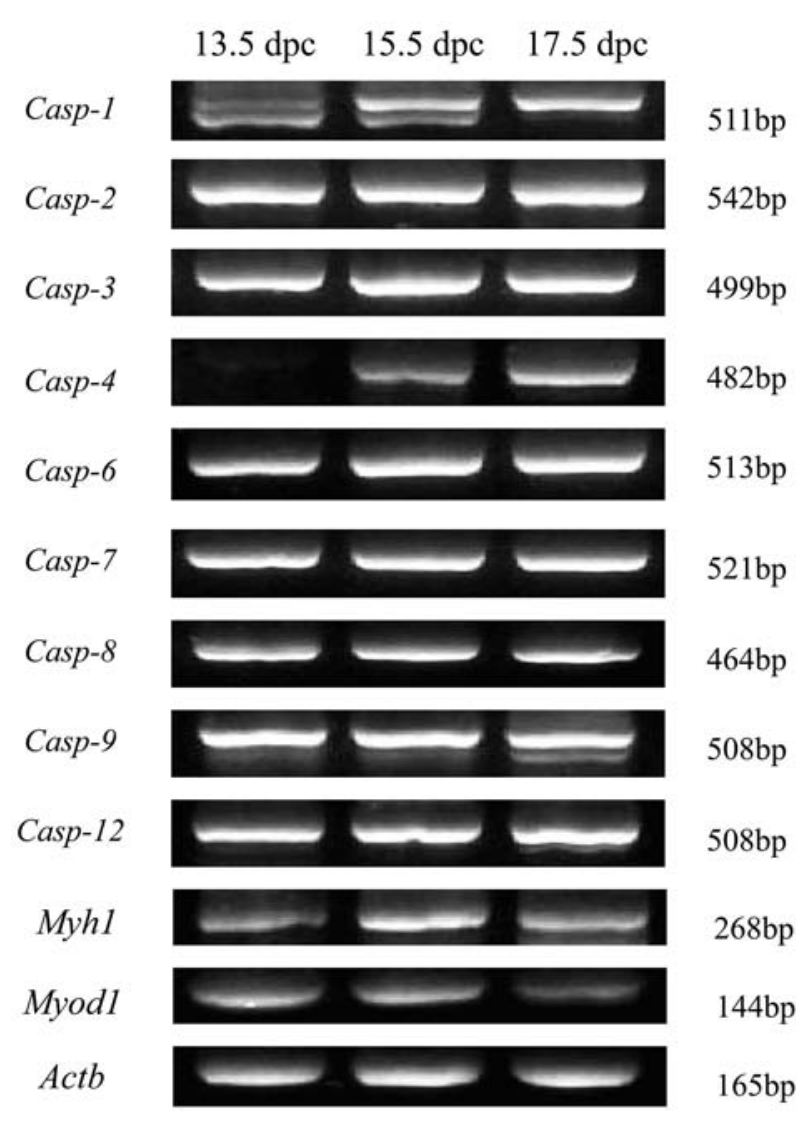

Fig. 1. Expression of the Casp family and muscle-specific genes confirmed by LMD-RT-PCR. Each Casp and muscle-specific gene is expressed in dorsal skeletal muscle tissues at 13.5, 15.5 and $17.5 \mathrm{dpc}$.

reverse-transcribed to cDNA with the reagent containing oligo dT (Invitrogen) and ReverTraAce (Toyobo, Osaka, Japan) for $1 \mathrm{hr}$ at $42^{\circ} \mathrm{C}$. Each cDNA adjusted to $1.0 \mu \mathrm{g} / \mathrm{m} l$ was used for PCR reaction with Ex Taq (Takara Bio, Tokyo, Japan) and the appropriate primer pairs, Casp-1, -2, -3, -4, 6, -7, -8, -9, -12, Myh1, MyoD, and Actb, as shown in Table 1. The amplified samples were electrophoresed with $1 \%$ agarose gel containing ethidium bromide, and finally photographed under an ultraviolet lamp.

Immunohistochemistry: The samples for histology were fixed with $4 \%$ paraformaldehyde at $4{ }^{\circ} \mathrm{C}$ overnight. Three to 5-micrometer-thick paraffin sections were routinely prepared, stained with hematoxylin-eosin and immunostained with the following procedure. Briefly, the deparaffinized sections were incubated with absolute methanol containing $0.5 \% \mathrm{H}_{2} \mathrm{O}_{2}$ for $20 \mathrm{~min}$ at room temperature; $10 \%$ normal goat serum for $30 \mathrm{~min}$ at room temperature; rabbit polyclonal antibodies for Casp-3 (1:800, Imgenex, San Diego, CA, U.S.A.), Casp-9 (1:800, Imgenex), Casp-12 (1:600, BioVision, Mountain View, CA, U.S.A.) and singlestranded (ss) DNA (1:300, Dako Cytomation, Kyoto, Japan) overnight at $4^{\circ} \mathrm{C}$; biotin-conjugated goat anti-rabbit IgG antiserum and then streptavidin-biotin complex (SAB-
PO(R) kit, Nichirei, Tokyo, Japan) for 30 min, respectively; 3,3'-diaminobenzidine tetrahydrochloride- $\mathrm{H}_{2} \mathrm{O}_{2}$ solution for $5 \mathrm{~min}$; and finally hematoxylin slightly for counter staining.

Immunostaining for myosin heavy chain (MyHC) was performed with the following sera or solutions instead of those mentioned above: $1 \%$ blocking reagent (Roche Diagnostics, Mannheim, Germany), mouse anti-MyHC antibody (1:300, Upstate, Temecula, NY, U.S.A.) as a primary antibody, a biotin-conjugated goat anti-mouse IgAGM antibody (1:100, Southern Biotech, Birmingham, AL, U.S.A.) and the Vectastain Elite ABC Standard Kit (Vector Laboratories, Burlingame, CA, U.S.A.).

In situ hybridization: cRNA probes for Casp-3, -9 and -12 were synthesized in the presence of digoxygenin-labeled UTP using a DIG RNA Labeling Kit in accordance with the manufacturer's protocol (Roche Diagnostics). The primer pairs for making each probe are shown in Table 1 .

Deparaffinized, proteinase K-digested sections were incubated with prehybridization and then hybridization buffers containing $50 \%$ formamide, $10 \mathrm{mM}$ Tris- $\mathrm{HCl}(\mathrm{pH}$ 7.6), $200 \mathrm{mg} / \mathrm{m} l$ tRNA, $1 \times$ Denhardt's solution $[0.02 \%$ bovine serum albumin, $0.02 \%$ polyvinyl pyrrolidone, and 0.02\% Ficoll PM400 (Amersham Pharmacia, Uppsala, Sweden)], $10 \%$ dextran sulphate, $600 \mathrm{mM} \mathrm{NaCl}, 0.25 \%$ SDS, 1 mM EDTA ( $\mathrm{pH} 8.0$ ) and a $1 \%$ sense or antisense RNA probe for $24 \mathrm{hr}$ at $63^{\circ} \mathrm{C}$. They were then incubated with $0.2 \%$ polyclonal sheep anti-digoxigenin Fab-fragments conjugated to alkaline phosphatase $(1: 2,000$, Nucleic Acid Detection Kit, Roche Diagnostics) for $1 \mathrm{hr}$ at room temperature. The signal was detected with a color-substrate solution (Roche Diagnostics) containing $4.5 \mu \mathrm{l}$ of nitroblue tetrazolium, $3.5 \mu l$ of X-phosphate $(0.75 \mathrm{ml}$ of 5-bromochloro-3-indolyl phosphate and $50 \mathrm{mg} / \mathrm{m} l$ toluidinium in dimethylformamide) in $1 \mathrm{~m} l$ of a solution composed of 100 $\mathrm{mM}$ Tris- $\mathrm{HCl}$ (pH 9.5), $100 \mathrm{mM} \mathrm{NaCl}$ and $50 \mathrm{mM} \mathrm{MgCl}_{2}$ in a dark room overnight at room temperature. After counterstaining with hematoxylin, the air-dried sections were directly immersed in xylene and finally mounted with cover slips.

For histoplanimetry using hybridized muscle tissues, the numbers (A) and areas (B) of positive signals of Casp-3, -9, -12 , and each tissue area $(C)$ were measured and analyzed using Photoshop ver. 6.0 (Adobe, Tokyo, Japan) and Image $\mathrm{J}$ ver. $1.32 \mathrm{j}$ (http://rsb.info.nih.gov/ij/), with the results finally presented as ratios $\mathrm{A} / \mathrm{C}$ and $\mathrm{B} / \mathrm{C}$.

Quantitative RT-PCR: Each cDNA sample obtained by the protocol described above was analyzed by using an Mx3000P qPCR system (Stratagene, La Jolla, CA, U.S.A.) including Brilliant SYBER Green QPCR Master Mix and the primer pairs for Casp-3, Casp-9, Casp-12, Fasl, Bax, Rock1, Myh1 and Myod1 shown in Table 1. All reactions were standardized with ROX fluorochrome, and corrected by amplification of the Actb primer pair.

Statistical analysis: All numerical results are shown as mean \pm S.E. and analyzed statistically by nonparametric methods. The Krusukal-Wallis test was used for comparing three populations, and multiple comparisons were per- 


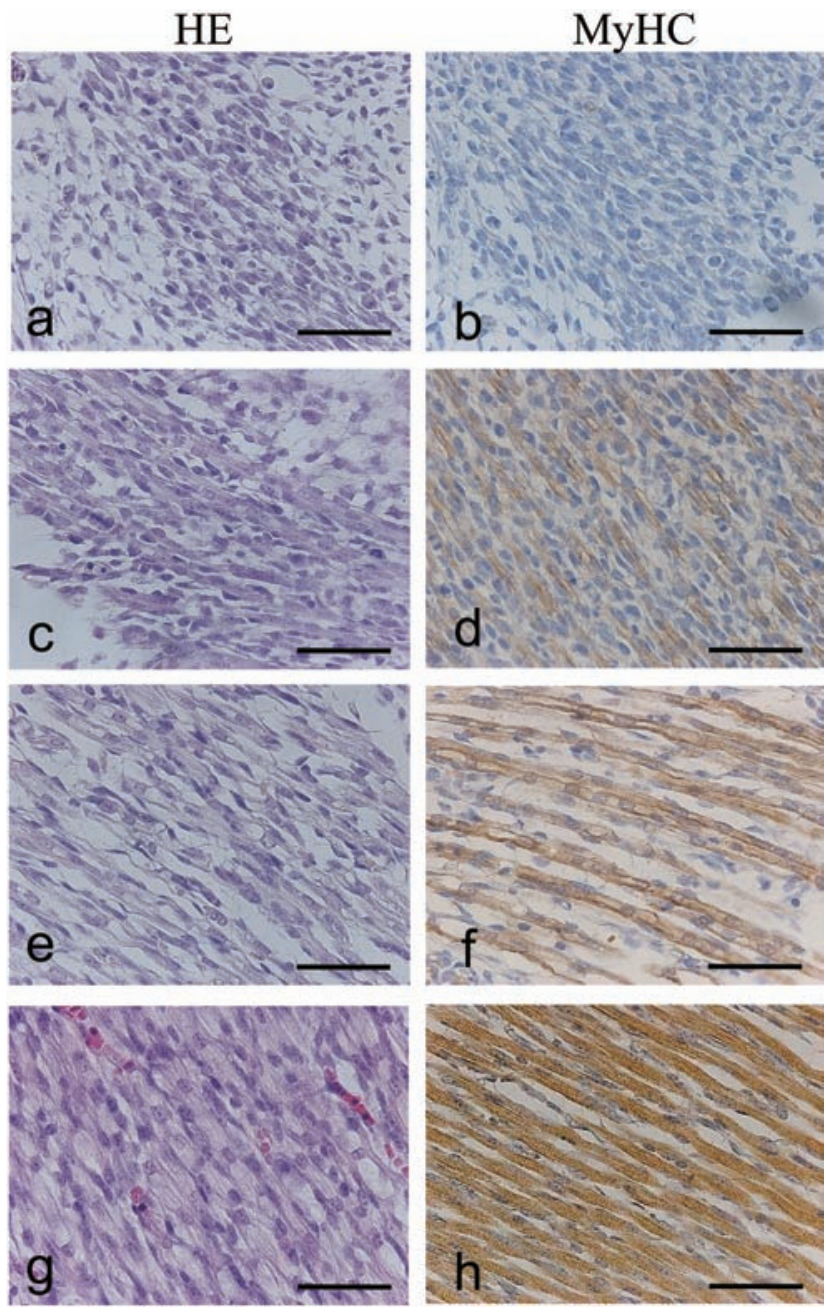

Fig. 2. Myogenesis in dorsal skeletal muscle in mouse embryos at $12.5(\mathrm{a}, \mathrm{b}), 13.5$ (c, d), 15.5 (e, f) and $17.5(\mathrm{~g}, \mathrm{~h}) \mathrm{dpc}$, shown with hematoxylin-eosin (HE: a, c, e, g) staining and myosin heavy chain (MyHC: b, d, f, h) immunostaining. MyHC-positive myoblasts are fused and then transformed into myotubes during embryonic development. Bars $=50 \mu \mathrm{m}$.

formed by Scheff's method when a significant difference was observed $(\mathrm{p}<0.05)$.

\section{RESULTS}

Immunohistochemistry for Casp family and apoptosis in embryonic skeletal muscles: Preliminarily, although Casp-4 expression on $13.5 \mathrm{dpc}$ was weak, the expression of almost all members of the Casp family, Casp-1, -2, -3, -4, -6, -7, -8, -9 , and -12 , including $M y h 1$ and $M y o D$ as muscle-specific genes, was confirmed by LMD-RT-PCR, suggesting that each Casp and muscle-specific gene was expressed in myo-

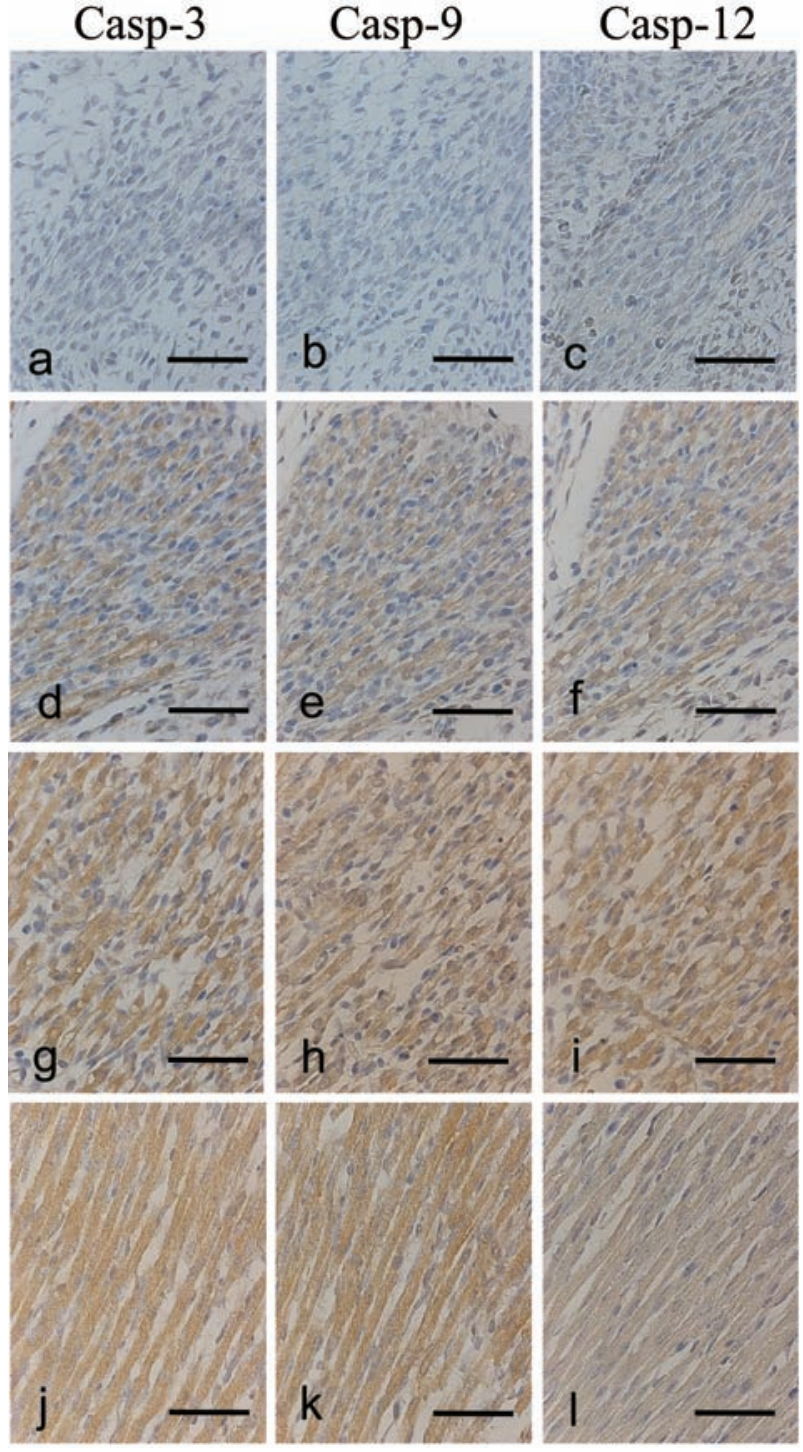

Fig. 3. Immunohistochemistry for Casp family (Casp-3: a, d, g, j; Casp-9: b, e, h, k; Casp-12: c, f, i, l) in mouse embryos at 12.5 (a, b, c), 13.5 (d, e, f), 15.5 (g, h, i) and 17.5 (j, k, l) dpc. Casp-12 starts to be detected from $12.5 \mathrm{dpc}$, whereas Casps-3 and -9 begin to be stained from $13.5 \mathrm{dpc}$. Bars $=50 \mu \mathrm{m}$.

genetic tissues at 13.5, 15.5 and $17.5 \mathrm{dpc}$ (Fig. 1). Because Casp-12, specific for the ER stress cascade, induces skeletal muscle differentiation in the $\mathrm{C} 2 \mathrm{C} 12$ cell line, we mainly analyzed the expression and distribution of Casp-3, -9 and $12[20,22]$.

Aggregation of myoblasts was observed at dorsal skeletal muscles from $12.5 \mathrm{dpc}$, when they fused to each other and were then transformed into myotubes in the process of embryonic development (Fig. 2). Immunoreaction for MyHC was sequentially strengthened in myoblasts, myotubes and then myocytes during embryogenesis (Fig. 2). In these tissues, Casp-12 started to be detected from $12.5 \mathrm{dpc}$, 


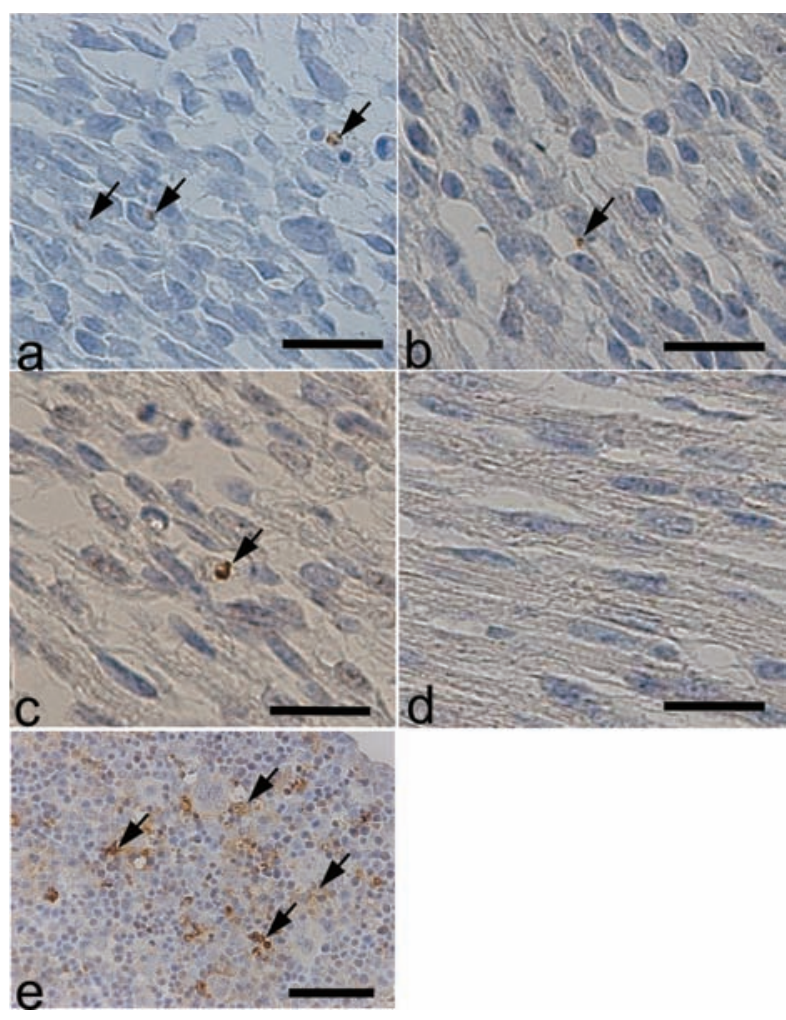

Fig. 4. Immunohistochemistry for ssDNA in developing muscles (a: $12.5 \mathrm{dpc}, \mathrm{b}: 13.5 \mathrm{dpc}, \mathrm{c}: 15.5 \mathrm{dpc}, \mathrm{d}: 17.5 \mathrm{dpc}$ ) and liver (e: $15.5 \mathrm{dpc}$ ). There are very few ssDNA-positive cells in skeletal muscles, whereas many ssDNA-positive cells are detected in liver. Bars $=20 \mu \mathrm{m}$ (a-d), $50 \mu \mathrm{m}$ (e). Arrow=positive cells.

strengthened in immunoreactivity at 13.5 and $15.5 \mathrm{dpc}$ and then weakened at $17.5 \mathrm{dpc}$, while the immunoreactivity for Casps-3 and -9 began to be detected from $13.5 \mathrm{dpc}$ and strengthened during the period of embryogenesis examined (Fig. 3). Interestingly, Casp-3 in some of the myoblasts and myotubes was localized not only in cytoplasm but also in the nucleus at $13.5 \mathrm{dpc}$.

Very few ssDNA-immunoreactive cells, apoptotic cells, were distributed in skeletal muscles during 12.5-17.5 dpc, although numerous Casp-positive cells were detected in this period (Fig. 4). Hepatic tissues, a positive control for apoptosis, showed many cells immunoreactive for ssDNA.

In situ hybridization for Casp family in embryonic skeletal tissues: The expression of mRNAs of Casp-3, -9 and -12 was detected by in situ hybridization, showing that they were distributed as dot-like structures in cytoplasm of myoblasts from $12.5 \mathrm{dpc}$ and tended to increase with the progression of the embryonic age (Fig. 5). Ratio of positive signal area and signal number in unit area increased significantly at $15.5 \mathrm{dpc}$, and decreased thereafter, showing similar tendencies for all three Casp genes (Fig. 6).

Quantitative RT-PCR for Casp family genes, muscle-specific genes and apoptosis-specific genes: The mRNA expression of the Casp family increased at $15.5 \mathrm{dpc}$ and then

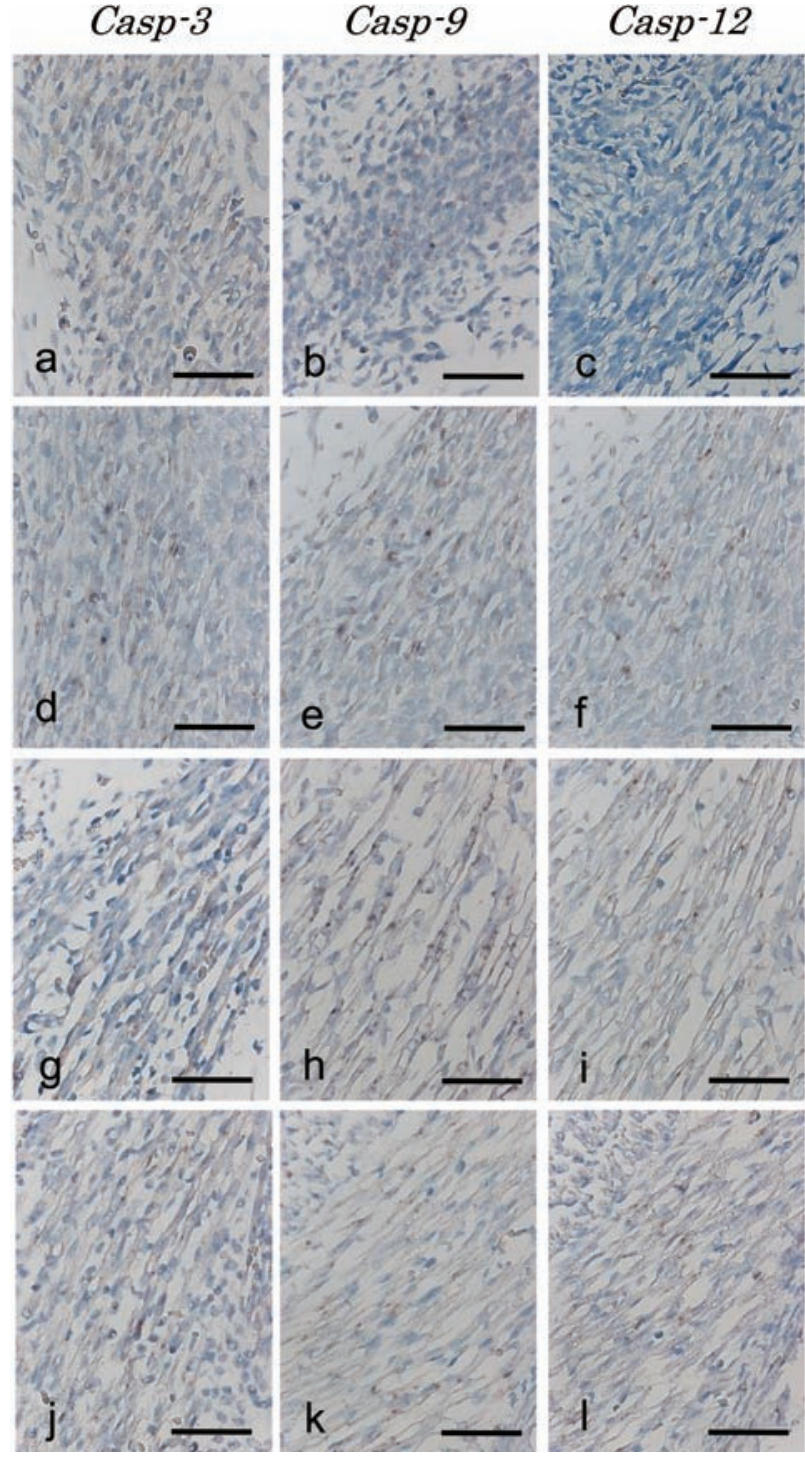

Fig. 5. The expression of mRNAs in Casp-3 (a, d, g, j), -9 (b, e, $\mathrm{h}, \mathrm{k})$ and -12 (c, f, i, l) detected by in situ hybridization at 12.5 (a, b, c), 13.5 (d, e, f), 15.5 (g, h, i) and 17.5 (j, k, l) dpc. The signals are distributed with dot-like structures on myoblasts from $12.5 \mathrm{dpc}$. Bars $=50 \mu \mathrm{m}$.

decreased significantly at $17.5 \mathrm{dpc}$ for Casp-3 and -9 , but not for -12 (Fig. 7). These tendencies were similar to those of the muscle-specific gene Myod1, but not Myh1. However, apoptosis-specific genes Fas 1 and Rock1 did not show any significant shift in mRNA expression. Only Bax decreased with the development of the embryo.

\section{DISCUSSION}

Casp family in mouse myogenesis: In the present study, it was confirmed that myogenesis proceeded from myoblasts at $12.5 \mathrm{dpc}$ into myotubes at $13.5 \mathrm{dpc}$. The expression of all 
a

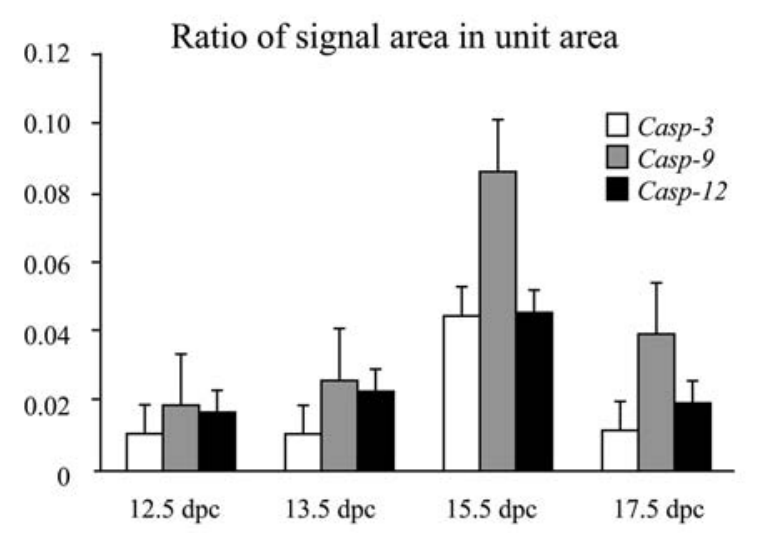

b

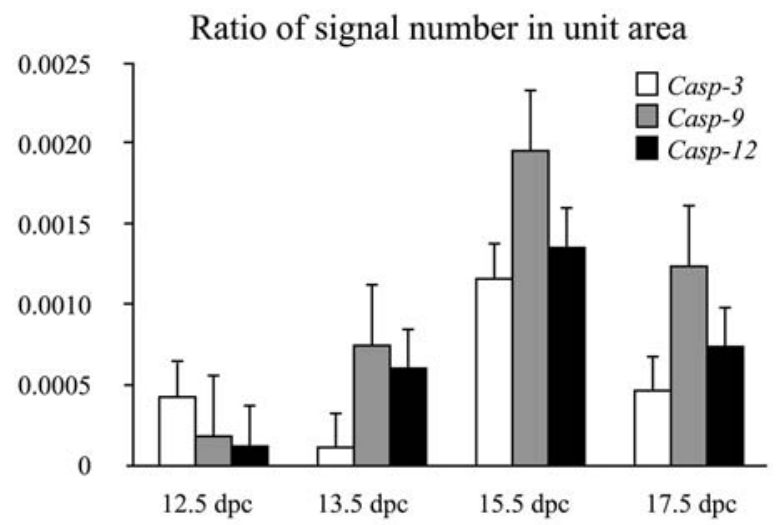

Fig. 6. Ratios of signal areas (a) and signal numbers (b) of Casp-3, -9 and -12 mRNAs in unit tissue areas from 12.5 to 17.5 dpc. Numerical values for the three genes increased at $15.5 \mathrm{dpc}$, and decreased thereafter. The number of animals $=2$. Numerical values show average \pm S.E.
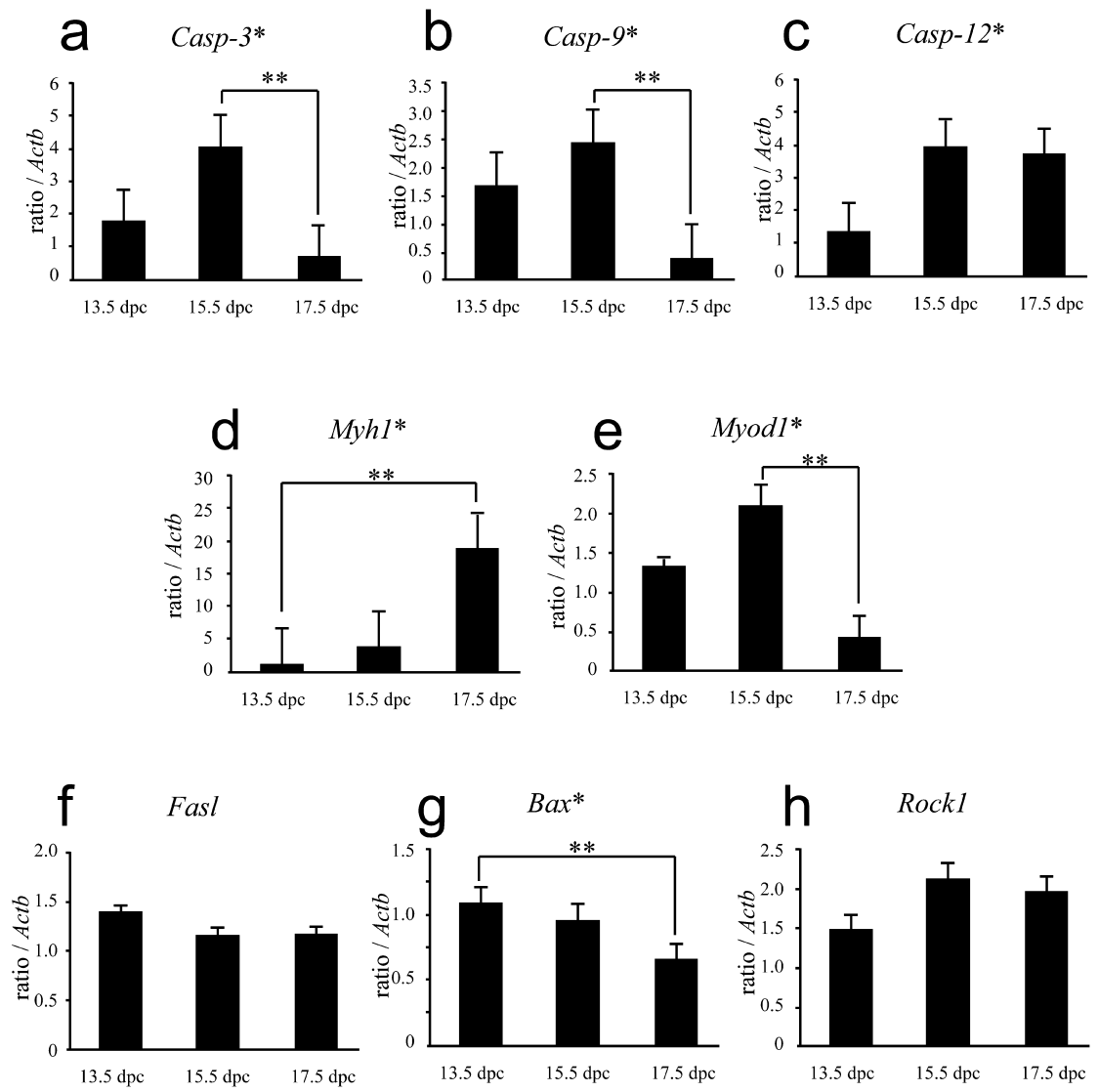

Fig. 7. The quantitative mRNA expression of the Casp family (a: Casp-3, b: Casp-9, c: Casp12), muscle-specific genes (d: Myhl, e: Myodl) and apoptosis-specific genes (f: Fasl, g: Bax, h: Rock1). Casp and Myod1, but not apoptosis-specific genes increased at $15.5 \mathrm{dpc}$ and then decreased. The number of animals $=3$. Numerical values show average \pm S.E. *: significance by nonparametric Kruskal-Wallis test $(\mathrm{p}<0.05)$. ${ }^{* *}$ : significance by multiple comparisons following the Kruskal-Wallis test (Scheffé's method) $(\mathrm{p}<0.05)$. 
Casp mRNAs examined was detected from $12.5 \mathrm{dpc}$ by in situ hybridization, whereas the localization of their proteins in myoblasts and myotubes was demonstrated at $12.5 \mathrm{dpc}$ for Casp-12, followed by at $13.5 \mathrm{dpc}$ for Casp-3 and -9 by immunohistochemistry. These results suggest that the Casp family starts to be expressed in accordance with onset of myogenesis.

The analysis of the Casp family indicated that there was a time difference between mRNA and protein expression of Casp-3, -9 and -12 . The mRNA expression of all Casps examined began at $12.5 \mathrm{dpc}$, peaked at the maximum level at $15.5 \mathrm{dpc}$, and then decreased at $17.5 \mathrm{dpc}$, whereas, of their products, only Casp-12 was in accord with mRNA expression, as Casp-3 and -9 were detected first at 13.5 dpc.

It is known that the Casp signaling starting from Casp-12, one of the initiators of the ER stress-specific cascade, activates the effector Casp group downstream, Casp-3 and then Casp-9 [7]. In early myogenesis, inadequate myoblasts are deleted by ER stress inducing Casp-12, with the result that only myoblasts obtaining the ability to withstand stress or having apoptotic resistance undergo myogenesis thereafter [21]. Additionally, the inhibitor of apoptosis (IAP) family suppresses the apoptotic pathway via specific inactivation of Casp-3, -7 and $-9[2,6]$. These facts indicate that the activation of Casp- 3 and -9 , but not -12 , is suppressed by the IAP family at $12.5 \mathrm{dpc}$ in myogenesis. Thereafter, to accelerate myogenesis, effector Casps, Casp-3 and -9 , are detected for the first time in myoblasts at $15.5 \mathrm{dpc}$, since they are not already suppressed by the IAP family.

Relationship between myogenesis, apoptosis and Casp family: Casp-3 is an effector for apoptosis, undergoing proteolysis in many cases such as by poly (ADP-ribose) polymerase (PARP), Casp-activated DNase and actin. During myogenesis, there was immunohistochemically very little apoptosis even if Casp-3 was detected in many myoblasts and myotubes, suggesting that the function of Casp-3 is not for apoptosis. Casp-3 is activated in lens epithelial cells and keratinocytes and plays an important role in eliminating the nucleus, but not in apoptosis, suggesting the possibility that it functions as a differentiation-inducing factor [13, 32].

In the present study, only few ssDNA-positive cells were detected during embryonic myogenesis and quantitative RT-PCR revealed that the expressions of the apoptosisrelated genes Fasl (death receptor pathway), Bax (mitochondria pathway) and Rock1 (downstream gene of Casp3) were not in accord with those of Casp family and the myogenesis-specific genes Myohl and Myofd1. These results contradicted the reports concerning the relations between myogenesis and Casps-mediated apoptosis in vitro [20-22]. However, gene expressions of Casp family including Casp12 ER stress signaling correlated with those of Myodl which is an essential factor for the initiation and maintenance of myogenesis [1]. These results indicate 1) that activation of the Casp family through the ER stress proceeds to myogenesis, but does not finally induce apoptosis, or 2) the existence of unknown factors that stimulate myogenesis directly but Casps indirectly.
Casp plays an important role as a family for differentiation: In apoptosis signaling, p38 alpha, which is related to the beginning and progression of apoptosis as a member of the mitogen-activated protein kinase (MAPK) family [10, 14], is simultaneously upregulated with muscular differentiation, and its suppression leads to delayed myogenesis [5, 34, 37]. Additionally, ER stress signaling promotes myoblast differentiation [22], suggesting an intimate relationship between the progression of myogenesis and activation of the Casp family. These results reveal that the so-called Casp family is originally associated with cell differentiation, promoting the morphological or biochemical changes. It is concluded that cell death, apoptosis, is a result of cell differentiation. This hypothesis might be supported by results using several types of knockout mice, including those for Casp-8, an initiator of death receptor signaling, Casp-9, an initiator of mitochondrial signaling, and Casp-3, an effector for apoptosis, in which all animals suffer from embryonic lethality $[16,17,30]$.

In conclusion, it is suggested that the Casp family is associated with myoblast differentiation, but not with apoptosis.

ACKNOWLEDGMENTS. This work was supported by Grants-in-Aid for Scientific Research from the Ministry of Education, Culture, Sports, Science, and Technology of Japan (19380162, 19658106). This research was chosen for the Encouragement Award (Undergraduate section) at the 146th Japanese Association of Veterinary Anatomists in Miyazaki (2008.9.24-26). We would like to sincerely thank all of the persons concerned.

\section{REFERENCES}

1. Arnold, H.H. and Braun, T. 2000. Genetics of muscle determination and development. Curr. Top. Dev. Biol. 48: 129-164.

2. Ashhab, Y., Alian, A., Polliack, A., Panet, A. and Ben Yehuda, D. 2001. Two splicing variants of a new inhibitor of apoptosis gene with different biological properties and tissue distribution pattern. FEBS Lett. 495: 56-60.

3. Black, B.L. and Olson, E.N. 1998. Transcriptional control of muscle development by myocyte enhancer factor-2 (MEF2) proteins. Annu. Rev. Cell Dev. Biol. 14: 167-196.

4. Coleman, M.L. and Olson, M.F. 2002. Rho GTPase signalling pathways in the morphological changes associated with apoptosis. Cell Death Differ. 9: 493-504.

5. Cuenda, A. and Cohen, P. 1999. Stress-activated protein kinase- $2 / \mathrm{p} 38$ and a rapamycin-sensitive pathway are required for C2C12 myogenesis. J. Biol. Chem. 274: 4341-4346.

6. Deveraux, Q.L. and Reed, J.C. 1999. IAP family proteins: suppressors of apoptosis. Genes Dev. 13: 239-252.

7. Faitova, J., Krekac, D., Hrstka, R. and Vojtesek, B. 2006. Endoplasmic reticulum stress and apoptosis. Cell. Mol. Biol. Lett. 11: 488-505.

8. Fernando, P., Kelly, J.F., Balazsi, K., Slack, R.S. and Megeney, L.A. 2002. Caspase3 activity is required for skeletal muscle differentiation. Proc. Natl. Acad. Sci. U.S.A. 99: 11025-11030.

9. Gallo, R., Serafini, M., Castellani, L., Falcone, G. and Alemà, S. 1999. Distinct effects of Rac1 on differentiation of primary avian myoblasts. Mol. Biol. Cell 10: 3137-3150. 
10. Graves, J.D., Gotoh, Y., Draves, K.E., Ambrose, D., Han, D.K., Wright, M., Chernoff, J., Clark, E.A. and Krebs, E.G. 1998. Caspase-mediated activation and induction of apoptosis by the mammalian Ste20-like kinase Mst1. EMBO J. 17: 2224 2234.

11. Hakem, R., Hakem, A., Duncan, G.S., Henderson, J.T., Woo, M., Sorengas, M.S., Elia, A., de la Pompa, J.L., Kagi, D., Khoo, W., Potter, J., Yoshida, R., Kaufman, S.A., Lowe, S.W., Penninger, J.M. and Mak, T.W. 1998. Differential requirement for caspase9 in apoptotic pathways in vivo. Cell 94: 339-352.

12. Hall, A. and Nobes, C.D. 2000. Rho GTPases: molecular switches that control the organization and dynamics of the actin cytoskeleton. Philos. Trans. Royal Soc. Lond. B Biol. Sci. 355: $965-970$.

13. Ishizaki, Y., Jacobson, M.D. and Raff, M.C. 1998. A role for caspases in lens fiber differentiation. J. Cell Biol. 140: 153158.

14. Juo, P., Kuo, C.J., Reynolds, S.E., Konz, R.F., Raingeaud, J., Davis, R.J., Biemann, H.P. and Blenis, J. 1997. Fas activation of the p38 mitogen-activated protein kinase signalling pathway requires ICE/CED-3 family proteases. Mol. Cell. Biol. 17: 24 35 .

15. Ko, H.W., Han, K.S., Kim, E.Y., Ryu, B.R., Yoon, W.J., Jung, Y.K., Kim, S.U. and Gwag, B.J. 2000. Synergetic activation of p38 mitogen-activated protein kinase and caspase-3-like proteases for execution of calyculin A-induced apoptosis but not $\mathrm{N}$-methyl-d-aspartate-induced necrosis in mouse cortical neurons. J. Neurochem. 74: 2455-2461.

16. Kuida, K., Zheng, T.S., Na, S., Kuan, C., Yang, D., Karasuyama, H., Rakic, P. and Flavell, R.A. 1996. Decreased apoptosis in the brain and premature lethality in CPP32-deficient mice. Nature 384: 368-372.

17. Kuida, K., Haydar, T.F., Kuan, C.Y., Gu, Y., Taya, C., Karasuyama, H., Su, M.S.S., Rakic, P. and Flavell, R.A. 1998. Reduced apoptosis and cytochrome c-mediated caspase activation in mice lacking caspase9. Cell 94: 325-337.

18. Megeney, L.A. and Rudnicki, M.A. 1995. Determination versus differentiation and the MyoD family of transcription factors. Biochem. Cell. Biol. 73: 723-732.

19. Molkentin, J.D., Black, B.L., Martin, J.F. and Olson, E.N. 1995. Cooperative activation of muscle gene expression by MEF2 and myogenic bHLH proteins. Cell 83: 1125-1136.

20. Nakagawa, T., Zhu, H., Morishima, N., Li, E., Xu, J., Yankner, B. A. and Yuan, J. 2000. Caspase-12 mediates endoplasmicreticulum-specific apoptosis and cytotoxicity by amyloid-beta. Nature 403: 98-103.

21. Nakanishi, K., Sudo, T. and Morishima, N. 2005. Endoplasmic reticulum stress signaling transmitted by ATF6 mediates apoptosis during muscle development. J. Cell Biol. 169: 555-560.

22. Nakanishi, K., Dohmae, N. and Morishima, N. 2007. Endoplasmic reticulum stress increases myofiber formation in vitro. FASEB J. 21: 2994-3003.

23. Olson, E.N. 1992. Interplay between proliferation and differentiation within the myogenic lineage. Dev. Biol. 154: 261-272.

24. Patapoutian, A., Yoon, J.K., Miner, J.H., Wang, S., Stark, K. and Wold, B. 1995. Disruption of the mouse MRF4 gene identifies multiple waves of myogenesis in the myotome. Development 121: 3347-3358.

25. Qu, G., Yan, H. and Strauch, A.R. 1997. Actin isoform utilization during differentiation and remodeling of $\mathrm{BC} 3 \mathrm{H} 1$ myogenic cells. J. Cell. Biochem. 67: 514-527.

26. Rudnicki, M.A., Schnegelsberg, P.N., Stead, R.H., Braun, T., Arnold, H.H. and Jaenisch, R. 1993. MyoD or Myf-5 is required for the formation of skeletal muscle. Cell 75: 13511359.

27. Sabourin, L.A. and Rudnicki, M.A. 2000. The molecular regulation of myogenesis. Clin. Genet. 57: 16-25.

28. Stockdale, F.E. 1992. Myogenic cell lineages. Dev. Biol. 154: 284-298.

29. Thornberry, N.A. and Lazebnik, Y. 1998. Caspases: enemies within. Science 281: 1312-1316.

30. Varfolomeev, E.E., Schuchmann, M., Luria, V., Chiannnikulchai, N., Beckmann, J.S., Mett, I.L., Rebrikov, D., Brodianski, V.M., Kemper, O.C., Kollet, O., Lapidot, T., Soffer, D., Sobe, T., Avraham, K.B., Goncharov, T., Holtmann, H., Lonai, P. and Wallach, D. 1998. Targeted disruption of the mouse caspase 8 gene ablates cell death induction by the TNF receptors, Fas/Apo1, and DR3 and is lethal prenatally. Immunity 9: 267-276.

31. Venuti, J.M., Morris, J.H., Vivian, J.L., Olson, E.N. and Klein, W.H. 1995. Myogenin is required for late but not early aspects of myogenesis during mouse development. J. Cell. Biol. 128: 563-576.

32. Weil, M., Raff, M.C. and Braga, V.M. 1999. Caspase activation in the terminal differentiation of human epidermal keratinocytes. Curr. Biol. 9: 361-364.

33. Woo, M., Hakem, R., Soengas, M.S., Duncan, G.S., Shahinian, A., Kögi, D., Hakem, A., McCurrach, M., Khoo, W., Kaufman, S.A., Senaldi, G., Howard, T., Lowe, S.W. and Mak, T.W. 1998. Essential contribution of caspase3/CPP32 to apoptosis and its associated nuclear changes. Genes Dev. 12: 806-819.

34. Wu, Z., Woodring, P.J., Bhakta, K.S., Tamura, K., Wen, F., Feramisco, J.R., Karin, M., Wang, J.Y. and Puri, P.L. 2000. p38 and extracellular signal-regulated kinases regulate the myogenic program at multiple steps. Mol. Cell. Biol. 20: 39513964.

35. Yagami-Hiromasa, T., Sato, T., Kurisaki, T., Kamijo, K., Nabeshima, Y. and Fujisawa-Sehara, A. 1995. A metalloprotease-disintegrin participating in myoblast fusion. Nature 377: 652-656.

36. Zheng, T.S., Schlosser, S.F., Dao, T., Hingorani, R., Crispe, I.N., Boyer, J.L. and Flavell, R.A. 1998. Caspase-3 controls both cytoplasmic and nuclear events associated with Fas-mediated apoptosis in vivo. Proc. Natl. Acad. Sci. U.S.A. 95: 1361813623.

37. Zetser, A., Gredinger, E. and Bengal, E. 1999. p38 mitogenactivated protein kinase pathway promotes skeletal muscle differentiation. Participation of the Mef2c transcription factor. $J$. Biol. Chem. 274: 5193-5200. 